\title{
A Comparison of Outcome of Age at Time Surgery between Younger and Older than 8 Years Old in Children with Congenital Muscular Torticollis
}

\author{
Nguyen Ngoc Hung, Le Tuan Anh \\ Vietnam National Hospital of Pediatrics, Hanoi, Vietnam \\ Email: ngocyenhung@gmail.com, huongtuan_bs@yahoo.com
}

How to cite this paper: Hung, N.N. and Anh, L.T. (2017) A Comparison of Outcome of Age at Time Surgery between Younger and Older than 8 Years Old in Children with Congenital Muscular Torticollis. Open Access Library Journal, 4: e4105.

https://doi.org/10.4236/oalib.1104105

Received: November 1, 2017

Accepted: November 26, 2017

Published: November 29, 2017

Copyright $\odot 2017$ by authors and Open Access Library Inc.

This work is licensed under the Creative Commons Attribution International License (CC BY 4.0).

http://creativecommons.org/licenses/by/4.0/

\begin{abstract}
Objective: Comparing results between surgical techniques and age at the time of surgery, and the effectiveness of surgical release unipolar or bipolar or both the sternocleidomastoid muscle for congenital muscular torticollis. Methods: This study was a retrospective study of 44 cases with sternocleidomastoid muscle. Children had operated release at mean age: 6.2 years old, at Pediatric Orthopaedic Department of National Hospital for Padiatrics between October 2006 and December 2015. Preoperative assessment included the age of child at presentation, any previous history of swelling in the neck in infancy. The degree of neck tilt and range of motion of the neck, flexion and limitation of rotation were recorded. The ultrasound, measure cervico-mandibular angle (CMA). Children had performed operation by Unipolar or Bipolar release. Operative results were according to assess by the score of Cheng et al. Results: The patients were divided into two Variants. Variant 1 (patients Younger than 8 Years) had 33 Patients and Variant 2 (patients Older than 8 Years) had 11 patients. Sex: Female: 18, Male 26; Mean age: 6.2 years old; Affect side: Right: 31, Left: 13; Operative Methods: Unipolar: 33, Bipolar: 11; Follow-up: 55.0 months (24 - 81). Improvement of limitation of Lateral Bending in Variant 1/Variant 2: 95.2\%/63.2\%; Improvement of Limitation of Rotation in Variant 1/Variant 2: 63.9\%/52.7\%; Improvement of Angle of Head Tilt in Variant 1/Variant 2: 86.6\%/66.3\%. Accepted result (Excellent + Good): 30/33 (90.9\% in Variant 1, 8/11 (72.7\%) in Variant 2. Conclusion: The diagnostic and evaluation of CMT requires a systematic team approach with members from fields of radiology, physiotherapy, craniofacial surgery, orthopaedics, neurosurgery and ophthalmology. The patients should be performed surgery for neck muscle release only if torticollis persists after the age of one year. The
\end{abstract}


rehabilitation should be performed soon after surgery.

\section{Subject Areas}

Orthopedics, Pediatrics

\section{Keywords}

Congenital Muscular Torticollis, Sternocleidomastoid Muscles, Translational Deformity, Facial Asymmetry

\section{Introduction}

Congenital muscular torticollis (CMT) reported incidence being 0.084\% - 3.92\%. [1] [2]. The clinical feature is the thickening and shortening of the sternocleidomastoid (SCM) muscle, which leads to head tilt and limited head rotation. Some infants could have a cough reflex while rotating the head to the affected side [3]. Children who have CTM with skull asymmetry or plagiocephaly may occur in the presence. Furthermore, facial asymmetry and scoliosis may also develop and become aggravated as the patient grows [4] [5].

Etiology could be intrauterine malposition, ischemic hypothesis, the intrauterine or perinatal compartment syndrome, birth trauma, and the hereditary hypothesis [6] [7]. CMT could be associated Congenital Dislocation of the Hip in $5 \%-10 \%$ of patients [8] [9].

$\mathrm{CMT}$, if left untreated, leads to progressive shortening of the affected sternocleidomastoid muscle (SCM) and the surrounding soft tissues of the neck [10].

Age at the time of surgery is the most important and usually has best outcomes when patients are between the ages of 1 and 4 years [11].

Main purposes of operation are cosmetic and functional improvements, and to relieve pain related [12].

The aim of our study was to analyze the results of treatment of CMT in children Younger and Older than 8 years with Operative methods Unipolar or Bipolar.

\section{Materials and Methods}

A retrospective study was carried out to evaluate the results of treatment whit operation performed from between October 2006 and December 2015 in 44 patients with CMT were diagnosed and treated surgically in the department of orthopaedics, Nation Hospital for Pediatrics. The patients were evaluated by physical examination, Roentgenography, and medical records. The operations were performed by single surgeon (Author). The study had the approval of the Ethical Review Committee of our Institute and was carried out in accordance with the tenets of the Declaration of Helsinki. 


\subsection{Clinical Diagnosis}

Average age at time operation was $6.2(\mathrm{SD}=32.2)$ years. There were 26 males and 18 females. The right CTM in 31 cases and the left CTM in 13 cases.

Preoperative assessment included the age of child at presentation, swelling in the neck in infancy, side of involvement, and gender of the child. The degree of neck tilt, the neck like side flexion, and range of motion (ROM) of the neck and limitation of rotation were recorded (Figure 1).

\subsection{Imaging Diagnosis}

Preoperative clinical photograph showing the child with congenital muscular torticollis affecting the right sternocleidomastoid muscle (Figure 1).

Preoperative Ultrasound, CMT was diagnosed when the thickness of the SCM muscle more $2 \mathrm{~mm}$ on affect side [13] (Figure 2).

The patients have excluded from study were the patients with neurodevelopmental disorders such as cerebral palsy, abnormal postures of the head and neck as related to ocular causes, intellectual disability and other conditions such as inflammation or infections of the neck or, structural abnormalities of the cervical spine.

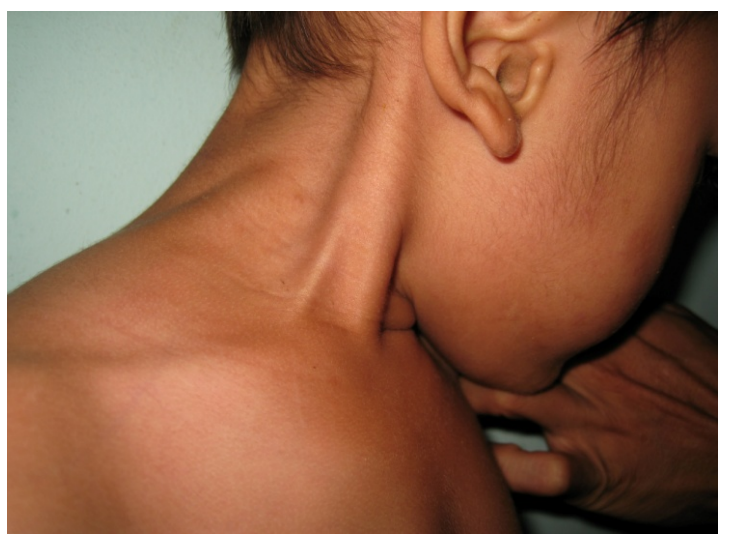

Figure 1. Patient with right CMT.

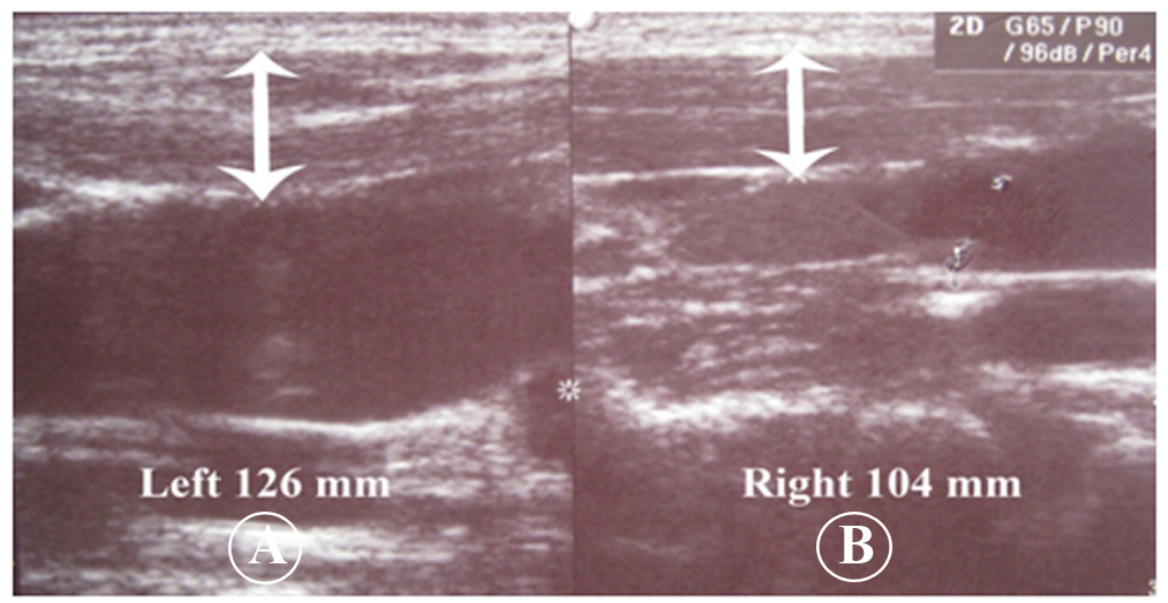

Figure 2. Ultrasound left CMT; Patient with left CMT: (A) left SCM is thicker than (B) right. 
The patients were divided into two Variants. In Variant 1 (patients Younger than 8 Years) had 33 Patients and Variant 2 (patients Older than 8 Years) had 11 patients.

The patients had performed sternocleidomastoid muscle release (unipolar in 33, bipolar in 11 (Table 5).

The average follow-up was 55. 0 (range, 24 - 79) months. At latest follow-up the patients have evaluated Neck motion (lateral bending, rotation), Craniofacial asymmetry, Head tilt, scarring, cosmetic and functional satisfaction, and lateral band formation were evaluated.

The authors propose cervico-mandibular angle (CMA) as a quantitatively evaluating head tilt from a simple x-ray (cervical spine AP view) (Figure 3).

Head Tilt. Angle was formed two lines: First line was through nose and Second line was through both upper edge of the shoulder. Use goniometer was measured this angle (Figure 4).

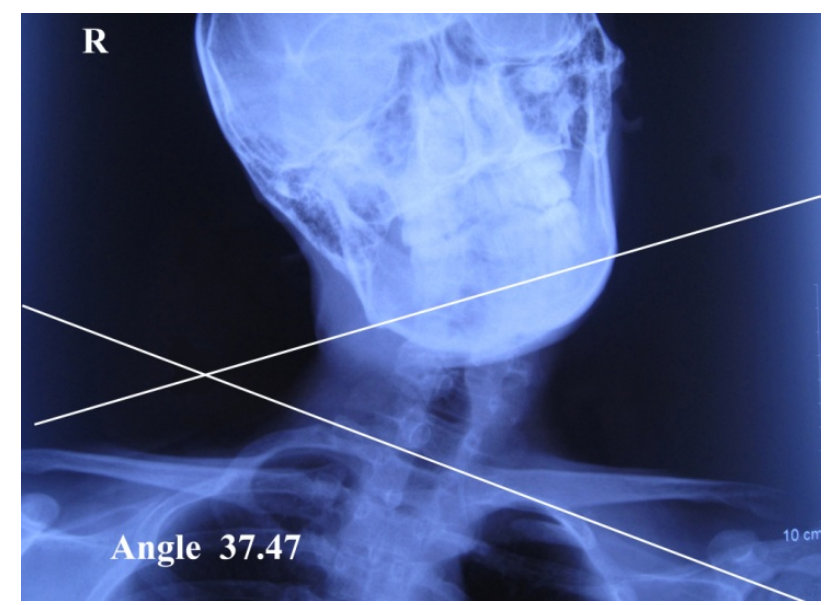

Figure 3. Cervico-mandibular angle (CMA) is measured between the line of the lower border of the $\mathrm{C} 7$ upper vertebral body and the line connecting the lower borders of both mandibles.

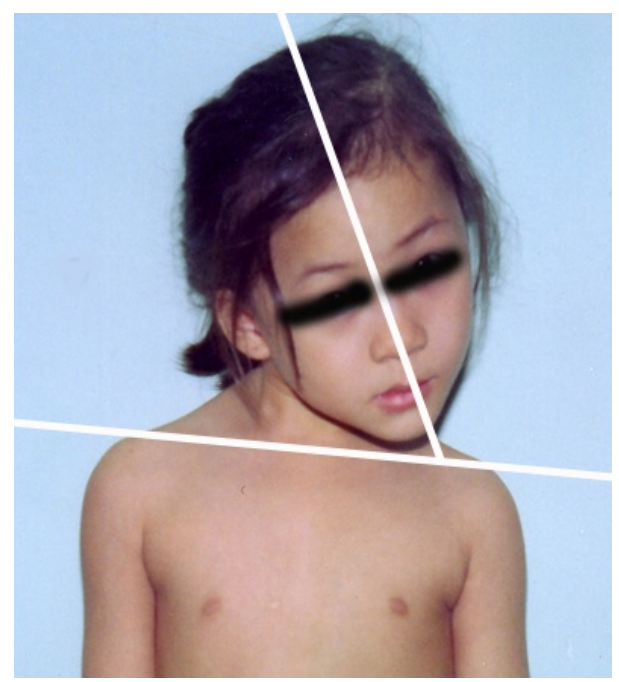

Figure 4. Measure head tilt. 


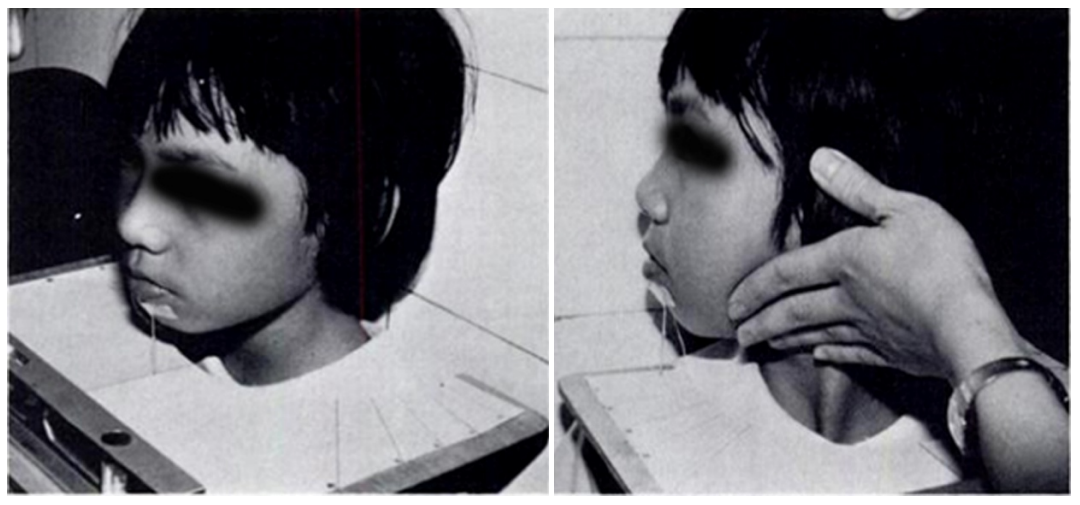

Figure 5. Measure head rotation.

Rotation. Shown in photograph, rotation measured using a plumb line attached to the centre of the chin while the head was rotated along a central vertical axis on a horizontal platform in front of the neck (Figure 5).

\subsection{Surgical Technique}

\subsubsection{Unipolar Tenotomy}

All children underwent soft tissue surgery under general anesthesia with precise neck positioning to allow intraoperative neck maneuvers to assess the completeness of surgical release. The endotracheal tube was well secured to avoid dislodgement during neck movements.

An intrascapular pad was placed to elevate the upper thorax and with neck extension supported on a padded ring. The upper torso was stabilized, and the ipsilateral arm was fixed with micropore tape to depress the shoulder. Perform to make the affected SCM more prominent and accessible to surgery. Transverse incision supraclavicular about $5 \mathrm{~cm}$ in line with the skin crease. The fascial covering over the clavicular and sternal heads was opened, and both the heads of the SCM were exposed. Using a Mixter forceps, the sternal head was elevated and 1 - 2 $\mathrm{cm}$ of the muscle with the fibrotic area was excised. Next, the clavicular origin was dissected free from the underlying fascia and incised along with the deep fascia.

\subsubsection{Bipolar Tenotomy}

In severe cases, with taut fascial or muscular bands on palpation and assistant surgeon supporting the head and neck to perform intraoperative rotational and translational maneuvers are difficult and fail. Performing a bipolar open tenotomy was done and additional incision through an upper. The proximal incision was made behind the ear and the muscle insertion was divided transversely just distal to the tip of the mastoid process.

After completely dividing sternocleidomastoid muscle, the patient's head was maneuvered from side to side to test the extent of the release. The wound was closed in layers using subcuticular 4/0 vicryl, without drain.

Post-operatively, the patient was immobilized in the corrected position in operation by plaster of Paris cast for 5 days and replaced by an adjustable torticollis brace an average of 8 weeks. The rehabilitation should be performed soon after surgery. 
Latest follow-up according to be Cheng and Tang system with modification [14] for obtaining final outcome.

\subsection{Statistical Analysis}

The data were analyzed with Epi Info 6.04 software public domain statistical software for epidemiology, developed by Centers for Disease Control and Prevention (CDC) in Atlanta, Georgia, USA,

http://wwwn.cdc.gov/epiinfo/html/prevVersion.htm. We performed the $\chi^{2}$ test for percentage and the t-student test for mean comparison between the preoperative and postoperative Variants. $P$-values $\leq 0.05$ were regarded as statistically significant. All readings were provided as average values together with the appropriate standard deviation.

\section{Results}

There were 44 patients dividing two Variant, Variant 1 with 33 and Variant 2 with 11 patients. Postoperative results at latest follow-up, the patients were evaluated according to Cheng et al. (Table 1). The Patient with Gestational (week) had longer than 37 weeks and Birth weight more than 3.310 gram for both Variant (Table 2).

\subsection{The Patients Illustration}
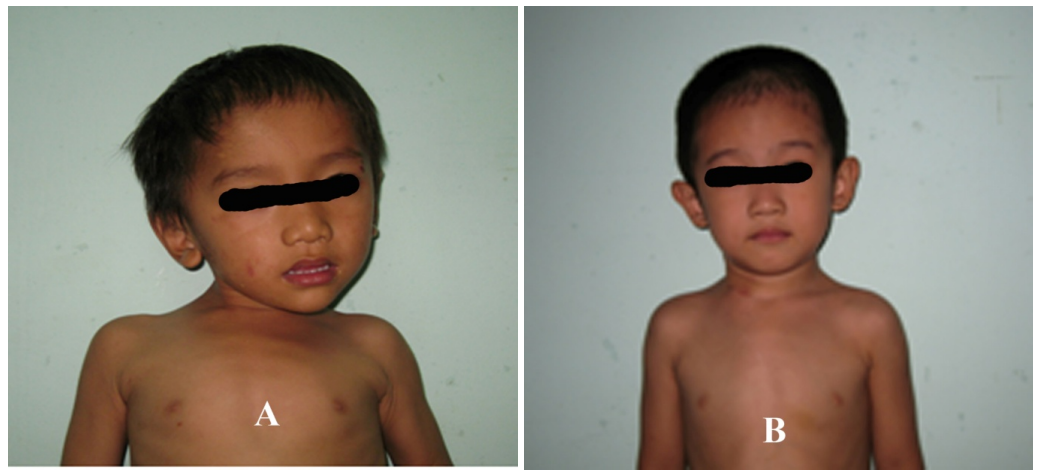

Figure 6. Number 16 in Table 5, Patient Male and are 5 years old, has Right CMT. The patient has Unipolar Released: (A) Pre-operation; and (B) Post-operative 34 months.
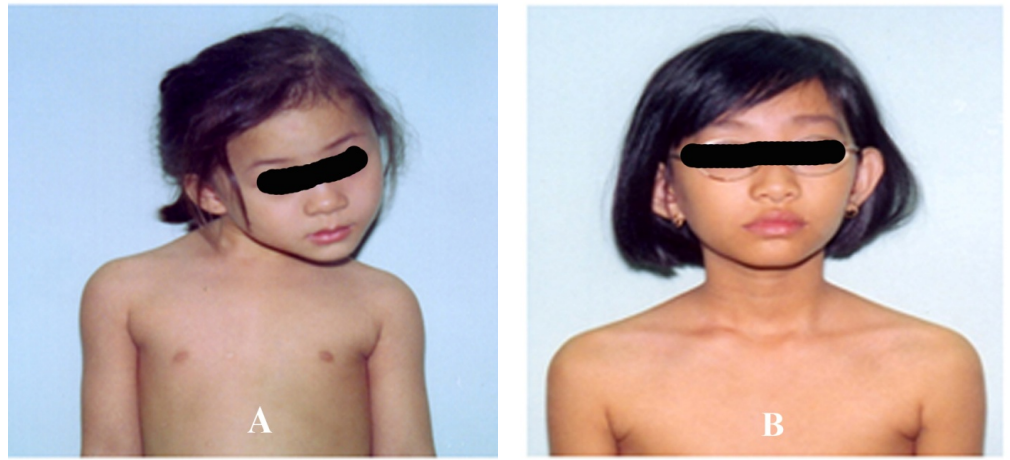

Figure 7. Number 9 in Table 6, Patient Female and 13 years old, have Right CMT. The patient has Bipolar Released: (A) Pre-operation; and (B) Post-operative 49 months. 


\subsection{Complication}

Losses of sternocleidomastoid column: 4 (9.1\%);

Bleeding or bruising: 2 (4.5\%);

Fracture of Clavicle: No;

Total: 6/44 (13.6\%).

\section{Discussion}

\subsection{Etiology}

Numerous theories have been proposed, but the true etiology of CMT remains uncertain. Various causes could be cause for CMT.

The birth trauma theory was most recognized. This theory proposes that the SCM muscle is torn at birth with the formation of a hematoma and formed fibrous in sternocleidomastoid muscle (Table 2). But, this cause is not made the muscle shortening or a mass [15]. Some reports suggested that the genetic etiology can play role in the development of CMT [6] [7]. According to those reports could be the basis of intrauterine or perinatal compartment syndrome [11]. It has been proposed that CMT could be the basis of intrauterine or perinatal compartment syndrome, based on injecting radio-opaque material into the SCM [11]. The intrauterine malposition etiology and according to this hypothesis with fact that 5\% - 10\% CMT children have Congenital Dislocation of the Hip or $6.5 \%$ have equinovarus [10]. The ischemic hypothesis could be intrauterine malposition because focal hypoxic ischemia in the SCM muscle [11].

\subsection{Diagnostic}

Diagnostical CMT must be undertaken to exclude other causes of abnormal neck posture such as infections of the ear, malformation of ear, other deformities around neck. The ultrasonography should be performed and this work is very important with diagnostical CMT [16] (Figure 2). The diagnostic and evaluation of torticollis have to be members from fields of physiotherapy, craniofacial surgery, radiology, ophthalmology, neurosurgery, and orthopaedics.

\subsection{Surgery}

Some surgeries could be performed for CMT such as unipolar, bipolar, and Z -plasty. The Surgical treatment CMT could be performed endoscopic method for sternocleidomastoid release to give good result [17]. In this study, we have performed unipolar in 33 cases and bipolar 11 cases (Table 3). Some reports to use of Botox injection to sternocleidomastoid muscle immediately affect to relax the tight muscle in CTM [18].

The improvement of ROM in Pre-Post operation shown that Improvement of limitation of lateral bending in Variant $1 /$ Variant 2: $95.2 \% / 63.2 \%(\boldsymbol{P}$ value $=$ 0.042455) with different signs; and Limitation of Rotation and Head Tilt they were not different signs (Table 4).

Age of patient at time of operation could have good result is younger 4 years 
old [19] or 8 years old [20] with accepted result was $90.6 \%$ and our study was 86.4\% (Figure 6 \& Figure 7).

In comparing the Surgical results in Variant 1 and Variant 2 with younger and Older than 8 years old (Table 5, Table 6); Accepted result (Excellent + Good):

Table 1. Scoring sheet for overall results from modified from Cheng et al. [14].

\begin{tabular}{|c|c|c|c|c|}
\hline Criterion & Excellent (3 point) & Good (2 point) & Fair (1 point) & Poor (0 point) \\
\hline Rotation deficits $\left({ }^{\circ}\right)$ & $<5$ & $6-10$ & $11-15$ & $>15$ \\
\hline Lateral bending deficits $\left({ }^{\circ}\right)$ & $<5$ & $6-10$ & $11-15$ & $>15$ \\
\hline Cramino fascial asymmetry (no, mild, moderate, severe) & No-Mild & Mild & Moderate & Severe \\
\hline Scar (no, mild, moderate, severe) & No-Mild & Mild & Moderate & Severe \\
\hline Subjective assessment (cosmetic and functional) & Excellent & Good & Fair & Poor \\
\hline Head tilt (CMA) & $<5$ & $6-10$ & $11-15$ & $>15$ \\
\hline Overall scores & $17-21$ & $12-15$ & $7-11$ & $<7$ \\
\hline
\end{tabular}

Table 2. Characteristics of birth of the children with CMT.

\begin{tabular}{|c|c|c|c|c|}
\hline \multirow{2}{*}{ Characteristics } & \multicolumn{2}{|c|}{ Vaginal delivery $n=33$} & \multicolumn{2}{|c|}{ Cesarean section $\mathrm{N}=11$} \\
\hline & Variant 1 & Variant 2 & Variant 1 & Variant 2 \\
\hline Number of subjects & 28 & 5 & 9 & 2 \\
\hline Gestational (week) & $37.1 \pm 1.42$ & $37.04 \pm 1.39$ & $37.02 \pm 1.40$ & $37.01 \pm 1.41$ \\
\hline Birth weight (gram) & $3450 \pm 361$ & $3386 \pm 328$ & $3312 \pm 400$ & $3411 \pm 315$ \\
\hline
\end{tabular}

Characteristics of birth of the children with CMT in Variant 1/Variant 2 of vaginal delivery with gestational (week): 7.1 $\pm 1.42 / 37.04 \pm 1.39$; With birth weight (gram): $3450 \pm 361 / 3386 \pm 328$. Characteristics of birth of the Children with CMT in Variant 1/Variant 2 of Cesarean section With Gestational (week): $37.02 \pm 1.40 / 37.01 \pm 1.41$; With Birth weight (gram): $3312 \pm 400 / 3411 \pm 315$.

Table 3. Data of the patient.

\begin{tabular}{|c|c|c|c|c|c|c|c|c|}
\hline & \multicolumn{2}{|c|}{ Sex } & \multirow{2}{*}{ Age (yr) } & \multicolumn{2}{|c|}{ Affected side } & \multicolumn{2}{|c|}{ Operated method } & \multirow{2}{*}{ Follow-up (month) } \\
\hline & $\mathrm{F}$ & M & & $\mathrm{R}$ & $\mathrm{L}$ & Unipolar & Bipolar & \\
\hline $\begin{array}{l}\text { Variant } 1 \\
(\mathrm{n}=33)\end{array}$ & 14 & 19 & $\begin{array}{l}4.2(2-7) \\
(\mathrm{SD}=1.7)\end{array}$ & 23 & 10 & 28 & 5 & $\begin{array}{c}56.9(24-79) \\
(\mathrm{SD}=11.7)\end{array}$ \\
\hline \multirow[t]{2}{*}{$\begin{array}{l}\text { Variant } 2 \\
(\mathrm{n}=11)\end{array}$} & 4 & 7 & $\begin{array}{c}12.5(8-15) \\
(\mathrm{SD}=2.3)\end{array}$ & 8 & 3 & 2 & 9 & $\begin{array}{c}54.1(24-76) \\
(\mathrm{SD}=14.4)\end{array}$ \\
\hline & 18 & 26 & $6.2(2-15)$ & 31 & 13 & 33 & 11 & $55.0(24-81)$ \\
\hline
\end{tabular}

Sex: Female 18, Male 26; Mean age: 6.2 years old; Affect side: Right: 31, Left: 13; Operative Methods: Unipolar: 33, Bipolar: 11; Follow-up: 55.0 months (24 - 81 ).

Table 4. Improvement of range of motion (ROM) in Pre-Post operation.

\begin{tabular}{|c|c|c|c|c|c|c|c|c|c|}
\hline & \multicolumn{3}{|c|}{ Mean angle of limitation of lateral bending } & \multicolumn{3}{|c|}{ Mean angle of limitation of rotation } & \multicolumn{3}{|c|}{ Mean angle of head tilt (ACM angle) } \\
\hline & Preop. & Postop. & Differences & Preop. & Postop. & Differences & Preop. & Postop. & Differences \\
\hline Variant 1 & 14.6 & 0.7 & 13.9 & 7.2 & 2.6 & 4.6 & 14.2 & 1.9 & 12.3 \\
\hline Variant 2 & 21.2 & 7.8 & 13.4 & 7.4 & 3.5 & 3.9 & 24.9 & 8.4 & 16.5 \\
\hline$P$ value & & & 0.042455 & & & 0.0858130 & & & 0.175734 \\
\hline
\end{tabular}

Improvement of limitation of lateral bending in Variant 1/Variant 2: 95.2\%/63.2\% ( $\boldsymbol{P}$ value $=0.042455)$; Improvement of Limitation of Rotation in Variant 1/Variant 2: 63.9\%/52.7\% $(\boldsymbol{P}$ value $=0.0858130)$; Improvement of Angle of Head Tilt in Variant $1 /$ Variant $2: 86.6 \% / 66.3 \%(\boldsymbol{P}$ value $=0.175734)$. 
Table 5. Data of patients younger than 8 years.

\begin{tabular}{|c|c|c|c|c|c|c|c|c|}
\hline Case & Sex & Side & Type of delivery & $\begin{array}{c}\text { Age at Operation } \\
\text { (Year) }\end{array}$ & $\begin{array}{c}\text { Fascial Asymmetric at } \\
\text { Follow-up }\end{array}$ & $\begin{array}{l}\text { Operated } \\
\text { method }\end{array}$ & $\begin{array}{l}\text { Length of follow-up } \\
\text { (Mo) }\end{array}$ & Result \\
\hline 1 & $\mathrm{~F}$ & $\mathrm{R}$ & Breech & 2 & No & Unipolar & 42 & Excellent \\
\hline 2 & M & $\mathrm{R}$ & Vertex, Forcep & 2 & Slight & Unipolar & 48 & Good \\
\hline 3 & $\mathrm{~F}$ & $\mathrm{~L}$ & Breech & 3 & Mild & Unipolar & 56 & Fair \\
\hline 4 & $\mathrm{~F}$ & $\mathrm{R}$ & Breech & 5 & No & Unipolar & 24 & Excellent \\
\hline 5 & $\mathrm{~F}$ & $\mathrm{R}$ & Vertex & 4 & No & Unipolar & 48 & Excellent \\
\hline 6 & M & $\mathrm{R}$ & Vertex, Forcep & 6 & Slight & Unipolar & 56 & Good \\
\hline 7 & M & $\mathrm{R}$ & Vertex, Forcep & 3 & Mild & Unipolar & 68 & Fair \\
\hline 8 & $\mathrm{~F}$ & $\mathrm{~L}$ & Breech & 3 & No & Unipolar & 38 & Excellent \\
\hline 9 & M & $\mathrm{R}$ & Vertex & 4 & No & Unipolar & 49 & Excellent \\
\hline 10 & M & $\mathrm{R}$ & Vertex, Forcep & 7 & Slight & Bipolar & 74 & Good \\
\hline 11 & $\mathrm{~F}$ & $\mathrm{R}$ & Breech & 5 & No & Unipolar & 58 & Excellent \\
\hline 12 & $\mathrm{~F}$ & $\mathrm{~L}$ & Breech & 5 & No & Unipolar & 65 & Excellent \\
\hline 13 & M & $\mathrm{R}$ & Breech & 3 & No & Unipolar & 57 & Excellent \\
\hline 14 & $\mathrm{~F}$ & $\mathrm{~L}$ & Vertex & 2 & Mild & Unipolar & 76 & Fair \\
\hline 15 & M & $\mathrm{R}$ & Breech & 3 & No & Unipolar & 48 & Excellent \\
\hline 16 & M & $\mathrm{R}$ & Vertex, Forcep & 4 & No & Unipolar & 34 & Excellent \\
\hline 17 & $\mathrm{~F}$ & $\mathrm{~L}$ & Vertex, Forcep & 5 & No & Unipolar & 59 & Excellent \\
\hline 18 & M & $\mathrm{L}$ & Breech & 6 & No & Bipolar & 51 & Excellent \\
\hline 19 & $\mathrm{~F}$ & $\mathrm{R}$ & Breech & 2 & Slight & Unipolar & 69 & Good \\
\hline 20 & $\mathrm{~F}$ & $\mathrm{R}$ & Vertex & 5 & No & & 54 & Excellent \\
\hline 21 & $\mathrm{~F}$ & $\mathrm{R}$ & Breech & 3 & No & Unipolar & 49 & Excellent \\
\hline 22 & M & $\mathrm{L}$ & Vertex, Forcep & 4 & Slight & Unipolar & 55 & Good \\
\hline 23 & $\mathrm{~F}$ & $\mathrm{R}$ & Vertex, Forcep & 6 & No & Bipolar & 70 & Excellent \\
\hline 24 & $\mathrm{~F}$ & $\mathrm{R}$ & Breech & 4 & No & Unipolar & 65 & Excellent \\
\hline 25 & M & $\mathrm{L}$ & Vertex & 5 & No & Unipolar & 48 & Excellent \\
\hline 26 & M & $\mathrm{R}$ & Breech & 4 & Slight & Unipolar & 58 & Good \\
\hline 27 & $\mathrm{~F}$ & $\mathrm{R}$ & Breech & 5 & No & Unipolar & 72 & Excellent \\
\hline 28 & $\mathrm{~F}$ & $\mathrm{~L}$ & Vertex & 7 & Slight & Bipolar & 62 & Good \\
\hline 29 & M & $\mathrm{R}$ & Breech & 6 & No & Bipolar & 47 & Excellent \\
\hline 30 & M & $\mathrm{R}$ & Vertex, Forcep & 2 & No & Unipolar & 79 & Excellent \\
\hline 31 & $\mathrm{~F}$ & $\mathrm{~L}$ & Vertex & 3 & No & Unipolar & 55 & Excellent \\
\hline 32 & $\mathrm{~F}$ & $\mathrm{R}$ & Vertex, Forcep & 5 & Slight & Unipolar & 58 & Good \\
\hline 33 & $\mathrm{~F}$ & $\mathrm{R}$ & Breech & 4 & No & Unipolar & 67 & Excellent \\
\hline
\end{tabular}


Table 6. Data of patients older than 8 years.

\begin{tabular}{|c|c|c|c|c|c|c|c|c|}
\hline Case & Sex & Side & $\begin{array}{l}\text { Type of } \\
\text { delivery }\end{array}$ & $\begin{array}{c}\text { Age at operation } \\
\text { (Year) }\end{array}$ & $\begin{array}{c}\text { Fascial asymmetric at } \\
\text { follow-up }\end{array}$ & $\begin{array}{l}\text { Operated } \\
\text { method }\end{array}$ & $\begin{array}{l}\text { Length of follow-up } \\
\text { (Mo) }\end{array}$ & Result \\
\hline 1 & M & $\mathrm{R}$ & Breech & 14 & Mild & Bipolar & 56 & Fair \\
\hline 2 & $\mathrm{~F}$ & $\mathrm{R}$ & Breech & 15 & No & Bipolar & 24 & Excellent \\
\hline 3 & $\mathrm{~F}$ & $\mathrm{~L}$ & Vertex, Forcep & 11 & No & Bipolar & 38 & Excellent \\
\hline 4 & M & $\mathrm{R}$ & Vertex & 10 & No & Unipolar & 49 & Excellent \\
\hline 5 & F & $\mathrm{L}$ & Breech & 11 & Mild & Bipolar & 56 & Fair \\
\hline 6 & $\mathrm{~F}$ & $\mathrm{R}$ & Breech & 8 & No & Unipolar & 65 & Excellent \\
\hline 7 & M & $\mathrm{R}$ & Breech & 12 & No & Bipolar & 57 & Excellent \\
\hline 8 & F & $\mathrm{L}$ & Vertex & 14 & Mild & Bipolar & 76 & Fair \\
\hline 9 & $\mathrm{~F}$ & $\mathrm{R}$ & Breech & 13 & No & Bipolar & 49 & Excellent \\
\hline 10 & M & $\mathrm{R}$ & Vertex, Forcep & 14 & Slight & Bipolar & 55 & Good \\
\hline 11 & F & $\mathrm{R}$ & Vertex, Forcep & 15 & No & Bipolar & 70 & Excellent \\
\hline
\end{tabular}

Female: 7, Mal: 4; Age at Operation: $12.5(8-15)$ SD = 2.3; Operated Method: Bipolar: 9; Unipolar: 2; Time of Follow-up = 54.1 (24 - 79) SD = 14.4; Surgical Result: Excellent 7/11 (63.6\%), Good 1/11 (9.1\%), Fair 3/11 (27.3\%), Right: 8. Left: 3. Accepted result (Excellent + Good): 30/33 (90.90\% in Variant 1, and $8 / 11(72.7 \%)$ in Variant $2(P$ Value $=0.310337)$. The both Variants were not different. Accepted result in both variants: $38 / 44(86.4 \%)$.

$30 / 33(90.9 \%)$ in Variant 1 , and $8 / 11(72.7 \%)$ in Variant 2 are not different $(\boldsymbol{P}$ Value $=0.310337)$.

\section{Conclusion}

The diagnostic and evaluation of CMT requires a systematic team approach with members from fields of radiology, physiotherapy, craniofacial surgery, orthopaedics, neurosurgery and ophthalmology. The patients should be performed surgery for neck muscle release only if torticollis persists after the age of one year. The rehabilitation should be performed soon after surgery.

\section{Limitations}

This study has several limitations. First, it was retrospective. Second, although patients were delivered by cesarean section, there were no records on the nature of the cesarean surgery (emergency or elective). Second, the possibility of perinatal trauma on the SCM muscle cannot be completely excluded, even for the cesarean section group. Third, this is an interim outcome report as most patients were not followed-up until skeletal maturity.

\section{References}

[1] Chen, M.M., Chang, H.C., Hsieh, C.F., Yen, M.F. and Chen, T.H. (2005) Predictive Model for Congenital Muscular Torticollis: Analysis of 1021 Infants with Sonography. Archives of Physical Medicine and Rehabilitation, 86, 2199-2203. https://doi.org/10.1016/j.apmr.2005.05.010

[2] Hsu, T.C., Wang, C.L., Wong, M.K., Hsu, K.H., Tang, F.T. and Chen, H.T. (1999) Correlation of Clinical and Ultrasonographic Features in Congenital Muscular Tor- 
ticollis. Archives of Physical Medicine and Rehabilitation, 80, 637-641. https://doi.org/10.1016/S0003-9993(99)90165-X

[3] Yim, S.Y., Lee, I.Y., Cho, K.H., Kim, J.K., Lee, I.J. and Park, M.C. (2010) The Laryngeal Cough Reflex in Congenital Muscular Torticollis: Is It a New Finding? American Journal of Physical Medicine \& Rehabilitation, 89,147-152. https://doi.org/10.1097/PHM.0b013e3181b7275b

[4] Binder, H., Eng, G.D., Gaiser, J.F. and Koch, B. (1987) Congenital Muscular Torticollis: Results of Conservative Management with Long-Term Follow-Up in 85 Cases. Archives of Physical Medicine and Rehabilitation, 68, 222-225.

[5] Canale, S.T., Griffin, D.W. and Hubbard, C.N. (1982) Congenital Muscular Torticollis, A long-Term Follow-Up. The Journal of Bone \& Joint Surgery, 64, 810-816. https://doi.org/10.2106/00004623-198264060-00002

[6] Cho, K.H., Kim, J.Y., Lee, I.Y. and Yim, S.Y. (2009) Congenital Muscular Torticollis in Siblings: A Case Report and Literature Review. Journal of Korean Academy of Rehabilitation Medicine, 33, 731-734.

[7] Engin, C., Yavuz, S.S. and Sahin, F.I. (1997) Congenital Muscular Torticollis: Is Heredity a Possible Factor in a Family with Five Torticollis Patients in Three Generations? Plastic and Reconstructive Surgery, 99, 1147-1150. https://doi.org/10.1097/00006534-199704000-00037

[8] Cheng, J.C., Tang, S.P., Chen, T.M., Wong, M.W. and Wong, E.M. (2000) The Clinical Presentation and Outcome of Treatment of Congenital Muscular Torticollis in Infants-Study of 1,086 Cases. Journal of Pediatric Surgery, 35, 1091-1096. https://doi.org/10.1053/jpsu.2000.7833

[9] Hummer, C.D. and MacEwen, G.D. (1972) The Coexistence of Torticollis and Congenital Dysplasia of the Hip. The Journal of Bone \& Joint Surgery, 54, 1255-1256. https://doi.org/10.2106/00004623-197254060-00014

[10] Ling, C.M. and Low, Y.S. (1972) Sternomastoid Tumor and Muscular Torticollis. Clinical Orthopaedics and Related Research, 86, 144-150.

[11] Canale, S.T., Griffin, D.W. and Hubbard, C.N. (1982) Congenital Muscular Torticollis: A Long-Term Follow-Up. The Journal of Bone \& Joint Surgery, 64, 810-816.

[12] Lim, K.S., Shim, J.S. and Lee, Y.S. (2014) Is Sternocleidomastoid Muscle Release Effective in Adults with Neglected Congenital Muscular Torticollis? Clinical Orthopaedics and Related Research, 472, 1271-1278. https://doi.org/10.1007/s11999-013-3388-6

[13] Yim, S.Y., Lee, I.Y., Cho, K.H., Kim, J.K., Lee, I.J. and Park, M.C. (2010) The Laryngeal Cough Reflex in Congenital Muscular Torticollis: Is It a New Finding? American Journal of Physical Medicine \& Rehabilitation, 89, 147-152.

[14] Cheng, C.Y. and Tang, S.P. (1999) Outcome of Surgical Treatment of Congenital Muscular Torticollis. Clinical Orthopaedics, 362, 190-200.

[15] Lidge, R.T., Bechtol, R.C. and Lambert, C.N. (1957) Congenital Muscular Torticollis, Etiology and Pathology. The Journal of Bone \& Joint Surgery, 39, 1165-1182. https://doi.org/10.2106/00004623-195739050-00015

[16] Cheng, J.C., Metreweli, C., Chen, T.M. and Tang, S. (2000) Correlation of Ultrasonographic Imaging of Congenital Muscular Torticollis with Clinical Assessment in Infants. Ultrasound in Medicine and Biology, 26, 1237-1241. https://doi.org/10.1016/S0301-5629(00)00301-X

[17] Burstein, F.D. and Cohen, S.R. (1998) Endoscopic Surgical Treatment for Congenital Muscular Torticollis. Plastic and Reconstructive Surgery, 101, 20-26. 
https://doi.org/10.1097/00006534-199801000-00004

[18] Luther, B.L. (2002) Congenital Muscular Torticollis. Orthopedic Nursing, 21, 21-29. https://doi.org/10.1097/00006416-200205000-00005

[19] Hollier, L., Kim, J., Grayson, B.H. and McCarthy, J.G. (2000) Congenital Muscular Torticollis and the Associated Craniofacial Changes. Plastic and Reconstructive Surgery, 105, 827-835. https://doi.org/10.1097/00006534-200003000-00001

[20] Shim, J.S., Noh, K.C. and Park, S.J. (2004) Treatment of Congenital Muscular Torticollis in Patients Older than 8 Years. Journal of Pediatric Orthopaedics, 24, 683-688. https://doi.org/10.1097/01241398-200411000-00016

Submit or recommend next manuscript to OALib Journal and we will provide best service for you:

- Publication frequency: Monthly

- 9 subject areas of science, technology and medicine

- Fair and rigorous peer-review system

- Fast publication process

- Article promotion in various social networking sites (LinkedIn, Facebook, Twitter, etc.)

- Maximum dissemination of your research work

Submit Your Paper Online: Click Here to Submit

Or Contact service@oalib.com 